\title{
PENGALAMAN SEKSUALITAS PEREMPUAN PASCA TAH BSO (TOTAL ABDOMINAL HYSTERECTOMYBILATERAL SALPINGO OOPHORECTOMY)
}

\author{
Ramdya Akbar Tukan*, Tintin Sukartini**, Esti Yunitasari** \\ *Mahasiswa Program Magister Keperawatan, Universitas Airlangga, \\ email: ramdyalovaa@gmail.com \\ **Fakultas Keperawatan Universitas Airlangga
}

\begin{abstract}
Introduction: Total Abdominal Bilateral Hysterectomy Salpingo Oophorectomy (TAH BSO) is one of the operations of gynecology which aims to remove the uterus, cervix and both tube and ovarian tubes. This study aims to explore the experience of female sexuality after the operation of TAH BSO at Haji Surabaya Hospital. Methods: This study used in-depth interview method to 7 participants who have conducted TAH BSO at Haji Surabaya Hospital. Result and analysis: This study result 2 findings: (1) Sexual activity after TAH BSO, Most patients experience a decrease in sexual desire, lubrication and lack of intensity sexual intercourse, but there are patients who can feel orgasm during sexual intercourse, (2) The response to the problem faced is husband's positive support and reduce the frequency of intercourse.
\end{abstract}

Discuss and Conclution: This study yielded 2 conclusions: (1) Patients after TAH BSO experience decreased sexual activity such as decreased sexual desire, lubrication, decreased quality of sexual relations, but there are patients who do not feel any lubrication and still can be feel the orgasm, It is caused by a good psychological condition,(3) Patients need the attention of husband and family. Suggestions for further research need to make more in-depth observations of the husband and the patient's family

Keywords: Sexuality Experience, Women, Total Abdominal Hysterectomy Bilateral Salpingo Oophorectomy

\begin{abstract}
Abstrak: Introduction: Total Abdominal HysterectomyBilateral Salpingo Oophorectomy (TAH BSO) adalah tindakan operasi gynecology yang bertujuan untuk menghilangkan uterus, serviks dan kedua tabung tuba serta ovarium. Penelitianbertujuan untuk mengeksplorasi pengalaman seksualitas perempuan setelah operasi TAH BSO. Methods: Penelitian menggunakan metode wawancara mendalamterhadap 7 partisipan pasca operasi TAH BSO di Rumah Sakit Haji Surabaya. Result and Analysis: Penelitian menghasilkan 2 tema: (1) Aktivitas seksual pasca TAH BSO yaitu sebagian besar pasien mengalami penurunan hasrat seksual, lubrikasi dan kurangnya intensitas hubungan seksual, namun ada pasien yang dapat merasakan orgasme saat melakukan hubungan seksual. (2) Respon terhadap masalah yang dihadapi adalah dukungan positif suami dan mengurangi frekuwensi hubungan seksual. Discuss and Conclution: Penelitian ini menghasilkan 2 kesimpulan:(1) pasien pasca TAH BSO mengalami penurunan aktivitas seksual seperti penurunan hasrat seksual, lubrikasi, penurunan kualitas hubungan seksual, tetapi terdapat pasien yang tidak merasakan adanya penuruanan lubrikasi dan masih bisa merasakan orgasme, hal tersebut disebabkan oleh kondisi psikologis yang baik,(2) Pasien membutuhkan perhatian suami dan keluarga. Saran untuk penelitian lebih lanjut perlu melakukan observasi lebih mendalam terhadap suami dan keluarga pasien.
\end{abstract}

Kata kunci: Pengalaman Seksualitas, Perempuan, TAH BSO 


\section{PENDAHULUAN}

Kesehatan merupakan hal yang harus mendapat perhatian khusus dalam kehidupan manusia. Terdapat beberapa ruang lingkup untuk menjamin bahwa manusia dapat memenuhi kesehatannya. Salah satunya adalah kesehatan reproduksi. Dalam kurun waktu ini terjadi banyak masalah kesehatan reproduksi, diantaranya penyakit yang berkaitan dengan sistem reproduksi sepertidispareunia, mioma uteri, adenomiosis, endometriosis, dan menometrorrhagia.

Salah satu tindakan medis yang dapat dilakukan adalah denganmelakukan pengangkatan rahim atau dikenal dengan nama histerektomi. Tindakan medis tersebut hingga saat ini menjadi kekhawatiran tersendiri bagi pasien. Dampak dari tindakan histerektomi terhadap fungsi seksual masih belum memiliki kepastian yang konsisten.banyak wanita melaporkan peningkatan fungsi seksual setelah histerektomi, yang mungkin karena menghilangkan gejala, sementara yang lain mengeluhkan disfungsi seksual sebagai akibat dari histerektomi. (Briedite, Ancane, Rogovska, \& Lietuviete, 2014).

Salah satu klasifikasi histerektomi yaitu TAH BSO (Total Abdominal Hysterectomy dan Bilateral Salpingo Oophorectomy). TAH BSO adalah salah satu tindakan operasi gynecology yang bertujuan untuk menghilangkan uterus, serviks dan kedua tabung tuba serta ovarium.

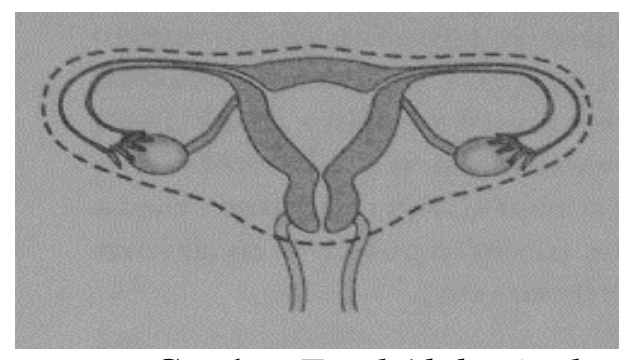

Gambar Total Abdominal

HysterectomyBilateral Salpingo

Oophorectomy (TAH BSO) Sumber:

(Gilly, 2010)
Diperkirakan $40 \%$ dari perempuan yang memiliki penyakit berkaitan dengan sistem reproduksi di seluruh dunia akan mengalami histerektomi pada usia 64 tahun dan indikasinya adalah untuk meringankan gejala dan meningkatkan kualitas hidup pada perempuan. (Briedite et al., 2014).

Di Indonesia khususnya di Rumah Sakit Umum (RSU) Haji Surabaya menunjukkan bahwa angka kejadian TAH BSO sebanyak 23 pasien pada tahun 2016 dan 34 pasien pada tahun 2015 ("Medical Record RSU Haji Surabaya," 2017)

Seksualitas perempuan yang telah menjalani pengangkatan rahim (uterus) dan indung telur (ovarium) ini perlu diperhatikan karena perempuan harus siap menghadapi kehidupan seksualitasnya. Permasalahan seksualitas bagi perempuan pasca pengangkatan rahim, serviks, tuba dan ovariumnya, dan perempuan tersebut memiliki suami, maka akan menjadi persoalan tersendiri yang dapat berakibat pada harmonisasi hubungan suami istri.Meneliti kesehatan reproduksi perempuan maka harus melihat secara menyeluruh melalui kesejahteraan fisik, mental dan sosialnya.

Penelitian ini bertujuan untuk mempelajari secara mendalam pengalaman pasien pasca dilakukan tindakan TAHBSO di Rumah Sakit Haji Surabaya.

\section{METODE}

Penelitian ini merupakan penelitian kualitatif dengan menggunakan tipe pendekatan fenomenologi, dilakukan pada pasien pasca TAH BSOdi Rumah Sakit Haji Surabaya.Partisipan dalam penelitian ini sebanyak 7 orang.Hasil wawancara di transkrip kemudian dianalisis menggunakan metode IPA(Interpretative Phenomenological Analisys).

Data dikumpulkan dengan metode wawancara mendalam (indepth interview) dan observasi pada sumber data primer dan dilakukan secara alamiah. Wawancara dilakukan dengan partisipan yang terlebih 
dahulu dilakukan seleksi dengan kriteria inklusi sebagai berikut; (1) Perempuan penderita kista ovarium dan mioma uteri (tumor jinak) yang telah selesai menjalani operasi TAH BSO lebih dari 6 minggu, (2)Perempuan yang masih menstruasi sebelum di operasi TAH BSO, (3)Memiliki pasangan (sudah menikah) dan tinggal serumah, (4)Bersedia menjadi responden dengan memberikan persetujuan yang telah peneliti sediakan, (5) Memahami bahasa indonesia dan mampu menceritakan pengalaman seksualitas

\section{HASIL PENELITIAN}

Peneliti menemukan 2tema penelitian meliputi : 1) Aktivitas seksual pasca TAH BSO; 2) Respon terhadap masalah yang dihadapi;. Tema dan sub tema dijabarkan sebagai berikut:

\section{Aktivitas Seksual Pasca TAH BSO}

Aktivitas seksual yang dialami partisipan setelah operasi TAH BSO adalah menurunnya hasrat seksual, penurunan lubrikasi, dan tingkat orgasme.

\section{Menurunnya Hasrat Seksual Kurang bergairah}

Seluruh partisipan menyatakan bahwa terjadi penurunan hasrat seksual ketika melakukan hubungan seksual. Seluruh partisipan mengungkapkan bahwa setelah operasi TAH BSO dalam hubungan seksual tidak lagi aktif menginisiasi, cenderung suami yang mengawali dan meminta untuk hubungan seksual.

".... Cuma dari saya itu kurang

$$
\text { bergairah }
$$$$
\text { gitu'(P5) }
$$

\section{Penurunan Lubrikasi}

1. Merasa vagina kering dan nyeri saat hubungan seksual

Sebagian partisipan menyatakan penurunan lubrikasi sehingga vagina terasa kering saat melakukan hubungan seksual. Meskipun vagina terasa kering tetapi tidak semua partisipan merasakan nyeri ketika berhubungan seksual.
Terdapat dua partisipan yang mengungkapkan bahwa penurunan lubrikasi setelah operasi TAH BSO menyebabkan rasa nyeri ketika berhubungan suami istri. Seperti yang diungkapkan partisipan di bawah ini:

“....setelah operasi itu pernah cuma sekali (berhubungan badan), itupun sakit (nyeri) karena kering ndak ada cairan beda dengan sebelum dioperasi. (P6)

\section{Merasa vagina kering dan tapi tidak} nyeri saat hubungan seksual

Partisipan yang lainnya justru menyatakan bahwa meskipun terjadi penurunan lubrikasi tetapi tidak merasakan nyeri ketika berhubungan suami istri. Seperti yang diungkapkan partisipan di bawah ini:

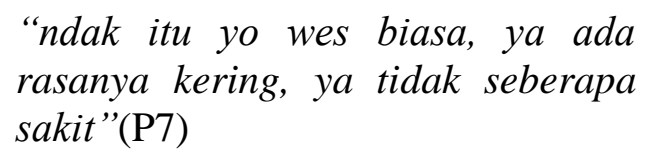
"ndak itu yo wes biasa, ya ada rasanya kering, ya tidak seberapa sakit"'(P7)

Meskipun terjadi penurunan lubrikasi, akan tetapi dari semua partisipan dalam penelitian ini yang tidak merasakan sakit atau nyeri adalah partisipan yang sejak awal sudah mampu menerima penyakit yang dialaminya secara ikhlas. Klien mengatakan masih merasakan cairan di vagina (tidak kering) pada saat berhubungan intim sehingga partisipan tidak merasakan nyeri ataupun sakit. Seperti yang diungkapkan partisipan di bawah ini:

$$
\begin{aligned}
& \text { “...tetap lendirnya ada kok, kadang } \\
& \text { banyak malahan, bisa orgasme } \\
& \text { berkali-kali, bicara tingkat sensitif } \\
& \text { divagina sensitifnya lebih sensitif } \\
& \text { yang dulu“(P2) }
\end{aligned}
$$

\section{Tingkat Orgasme}

1. Masih bisa orgasme

Menurunnya hasrat seksual ketika melakukan hubungan seksual dapat diminimalisir dengan rangsangan yang diberikan oleh suami. Partisipan menyatakan bahwa hasrat seksual memang 
sudah menurun, tetapi hasrat seksual masih dapat dirasakan partisipan apabila suami mampu memberikan rangsangan yang ekstra. Terdapat Satu partisipan yang menyatakan masih bisa merasakan orgasme ketika hubungan seksual. Seperti yang diungkapan partisipan dibawah ini:

“...bisa bisa orgasme, berkali-kali ”(P2)

\section{Respon terhadap masalah yang di hadapi}

Partisipan merasakan ada perbedaan terhadap hubungan seksual yang dialami sebelum dan sesudah operasi TAH BSO. Dalam penelitian ini digambarkan ada beberapa upaya yang dilakukan oleh partisipan. Pertama, dukungan positif suami dan kedua adalah mengurangi frekuensi hubungan seksual.

\section{Dukungan Positif Suami}

Upaya yang dilakukan dalam mengatasi masalah seksual adalah dengan membangun suasana batin yang nyaman antara suami dan istri. Seluruh partisipan mengungkapkan dukungan positif suami dapat membantu mengatasi tingkat stres yang dialami partisipan setelah operasi TAH BSO.

Dukungan positif suami tersebut adalah pengertian, perhatian, mendukung, memberi semangat, bertanggung jawab. Adapun pernyataan partisipan terkait hal tersebut di atas adalah sebagai berikut:

"pokoknya kita saling mengerti, gak jadi masalah wes biasa aja”(P1)

"ibu gak usah angkat - angkat ginigini, suapaya pulih dulu'( $\mathrm{P} 1)$

Mendukung, memangnya sakit sabar gini-gini gitu $(\mathrm{P} 1)$

\section{Mengurangi Frekuensi Hubungan Seksual}

Partisipan mengungkapkan bahwa dengan mengurangi frekuensi hubungan seksual dapat mambantu mengurangi keluhan hubungan seksual. Setelah operasi TAH BSO partisipan mengungkapkan terjadi penurunan frekuensi hubungan seksual yang terklasifikasikan menjadi Tiga yaitu:

Antara satu hingga dua kali dalam satu minggu

"Ndak tentu, jarang-jarang ya,

kadang seminggu sekali"(P7)

Antara satu hingga dua kali dalam satu bulan

“..sebulan sekali ...”(P5)

Satu bulan tidak melakukan hubungan seksual

"halah.. jarang. Satu bulan atau dua bulan loh jarang mbak...".(P3)

\section{PEMBAHASAN}

\section{Aktivitas Seksual Pasca TAH BSO}

Hasil penelitian ini menunjukan bahwamayoritas aktivitas seksual pasien pasca TAH BSO menglami permasalahan yaitu penurunan lubrikasi, menurunnya hasrat seksual, kurangnya intensitas hubungan seksual. Kondisi tersebut dikarenakan saat melakukan hubungan seksual pasien merasakan nyeri. Permasalahan tersebut dikarenakan setelah dilakukan pengangkatan rahim terjadi perubahan fisiologis yang berdampak pada permasalahan seksualitas perempuan yaitu berkurangnya hormon estrogen, akibatnya vagina terasa kering karena menurunnya lubrikasi (Windhu, 2009). Hasil penelitian ini sejalan dengan penelitian yang dilakukan Wulandari, Rachman \& Nisman(2016) di RSUP Sardjito Yogyakarta dalam penelitian tersebut dijelaskan bahwa hampir setiap responden (pasien yang operasi TAH-BSO) memiliki pengalaman nyeri pada saat melakukan hubungan seksual.

Penelitian yang mendukung adalah Bayram dan Beiji NK (2010) yang menjelaskan bahwa masalah seksual setelah histerektomi meliputi dispareunia, penurunan pelumasan atau lubrikasi, libido rendah, dan tidak mengalami orgasme.

Penelitian ini juga menjelaskan bahwa tidak semua perempuan yang menjalani operasi TAH-BSO merasakan 
gangguan seksual, meskipun secara fisiologis terjadi penurunan lubrikasi pada vagina. Pasien masih dapat merasakan orgasme. Penelitian ini sesuai dengan hasil penelitian Roovers, van der Bom, van der Vaart, \& Heintz, (2003), bahwa orgasme eksternal yang disebabkan oleh stimulasi pada klitoris tidak terpengaruh oleh histerektomi sedangkan orgasme internal yang disebabkan stimulasi pada ujung saraf dalam pleksus uterovaginal hilang oleh histerektomi dengan pengangkatan servik. Penelitian lain yang sejalan adalah Hoffmann, Schei dan Eriksson(2006) menyimpulkan bahwa mayoritas wanita yang melakukan histerektomi sub total dan total tidak merasakangangguan kepuasan seksual, penyebab utama gangguan justru pada pengalaman seksual negatif sebelum dilakukan operasi histerektomi.

Kondisi tersebut lebih dikarenakan kemampuan respon seksual yang dilakukan perempuan pada saat melakukan hubungan seksual. Respon seksual ini muncul karena pasien tidak lagi memikirkan penyakitnya, merasa sudah sembuh dan menjadi perempuan normal kembali. Kondisi tersebut lebih memudahkan pasien untuk membangun fantasi seksual ketika melakukan hubungan seksual karena tidak lagi memiliki beban penyakit.

Hasil ini sejalan dengan penelitian Rahimzadeh, Nazemi, \& Alizadeh (2002) yang menjelaskan bahwa histerektomi mempengaruhi kontraksi vagina dan penurunan lubrikasi akan tetapi tidak menyebabkan rasa sakit pada saat melakukan hubungan seksual.Selain itu penelitian ini didukungdengan interpretasi klinik dari FSFI, fungsi seksual wanita terdiri dari enam domain struktur yang mengidentifikasi, salah satunya adalah hasrat (desire) yang merupakan cerminan dasar psikologis tentang motivasi dan dorongan yang ditandai oleh khayalan seksual dan keinginan untuk melakukan aktivitas seksual (Kuppermann dkk., 2005). Selain itu penelitian lain yeng mendukung adalah (Berek, 2007; Wulandari, Rachman dan Nisman (2016)).Dalam aktivitas seksual yang timbul dyspareunia maka mengakibatkan perubahan hasrat seksual. Jika kondisi mengenai dyspareunia dapat diatasi maka dapat meningkatkan hasrat dan frekuensi seksual.

\section{Respon Terhadap Masalah yang Dihadapi}

Penelitian ini menjelaskan bahwa respon terhadap masalah yang di hadapi pasien pasca TAH BSOadalah dukungan positf suami dan mengurangi frekuensi hubungan seksual. Pengaruh dukungan positif suami sangat berperan dalam membantu mengatasi permasalahan yang di hadapi pasien. Hal ini sejalan dengan penelitian yang dilakukan Liamputtong dan Abboud (2005) yang mana dukungan suami merupakan hal yang sangat penting untuk memperkuat proses penerimaan individu terhadap perubahan yang dialaminya. Hasil penelitian ini juga sesuai dengan apa yang dikemukakan Lieberman (1992) mengemukakan bahwa secara teoritis dukungan sosial dapat menurunkan kecenderungan munculnya kejadian yang dapat mengakibatkan permasalahan seksual pasien pasca histerektomi.

Selain itu mengurangi frekuensi hubungan seksual juga memiliki peran besar dalam mengurangi permasalahan pasien. Gangguan fisiologis dan anatomis pasca TAH BSO memang berpengaruh terhadap frekuensi hubungan seksual pasien. Hal ini sama dengan hasil penelitian yang dilakukan Illiano, Ester et.al (2016) Frekuensi hubungan seksual tergantung pada banyak faktor anatomis dan psikologis, terutamaInteraksi antarakesejahteraan emosional, keintiman dengan pasangan, kualitas hidup dan kesehatan fisik.

\section{Kesimpulan:}


Kesimpulan dari penelitian ini yaitu : 1) Perempuan pasca TAH BSO mengalami penurunan aktivitas seksual seperti penurunan hasrat seksual, penurunan tingkat lubrikasi hingga mengalami penurunan kualitas hubungan seksual, tetapi terdapat pasien yang tidak merasakan adanya penuruanan lubrikasi bahkan masih bisa merasakan orgasme pada saat melakukan hubungan seksual,hal tersebut disebabkan oleh kondisi psikologis serta konsekuensi medis pasca TAH BSO, 2) Perempuan pasca TAH BSO membutuhkan perhatian dari lingkungan sosial di sekitar, terutama suami yang ditunjukan melalui penguatan psikologis serta perhatian fisik salah satunya dengan pengurangan intesitas hubungan seksual;

\section{Daftar Pustaka}

Bayram, G.O,.\& Beji, N.K. (2009). Psychosexual adaptation and quality of life after hysterectomy. Original paper. DOI 10.1007/s11195-009-9143-y. http://www.springerlink.com/ diperoleh tanggal 23 Februari, 2010.

Berek,Jonathan S. Berek \& Novak's. (2007) Gynecology, 14th Edition. 2007. Lippincott Williams \& Wilkins; hal 521

Briedite, I., Ancane, G., Rogovska, I., \& Lietuviete, N. (2014). Quality of Female Sexual Function after Conventional Abdominal Hysterectomy - Three Months ' Observation, 2014(7), 26-31.

Hoffmann, Schei, Eriksson. (2006). Sexual experience of partners after hysterectomy, comparing subtotal with total abdominal hysterectomy. Volume 85, Issue 11. Page:1389-1394. http://www.tandfonline.com/doi/full/10 $\underline{.1080 / 00016340600917316}$

Illiano, Ester.et.al. 2016.Hysterectomy and Sexuality.Tersedia:http://www.avidscie nce.com/wp-

content/uploads/2017/01/HYST-16-

02.pdf (04 juli 2017)

Kuppermann. (2005). Sexual Functioning after Total Compared with Supracervical Hysterectomy: A Randomized $\mathrm{T}$ rial. Obstet Gynecol, 105(6), 1309-1318.

Liamputtong \& Abboud, L. (2005)."When pregnancy fails: coping strategies, support networks and experiences with health care of ethnic women and their partners". Journal of reproductive andinfant psychology, 23 (1), 3-18

Lieberman. (1992). The Effect of Social Support On Respond On Stress. (Bretnitz\&Golberger, Ed.) (Handbook o). London: Collier Mac Millan Publisher

Polit, D. F., \& Beck, C. T. (2010). Essential Of Nursing Research Appraising Evidence For Nursing Practice (Sevent). Philadelphia: Lippincott Williams \& Wilkins.

Rahimzadeh, Nazemi, \& Alizadeh (2002). A Survey About The Effect Of Hysterectomy On Sexual Dysfunction In Patients Underwent Surgery InPatients Underwent Surgery In Sanandaj Behsat hospital. Scientific Journal of Kurdis - Tan University of Medical Sciences, 6(2), 46-51. Retrieved from http://en.journals.sid.ir/ViewPaper.as $\mathrm{px}$ ?ID=27179

Roovers, J., van der Bom, J., van der Vaart, C., \& Heintz, A. (2003). Hysterectomy and sexual wellbeing: prospective observational study of vaginal hysterectomy, subtotal abdominal hysterectomy, and total abdominal hysterectomy. BMJ, 327, 774-777. Retrieved from 
https://www.ncbi.nlm.nih.gov/pubme $\underline{\mathrm{d} / 14525872}$

Windhu. (2009). Disfungsi Seksual: Tinjauan

Fisiologi dan Patologis terhadap Seksualitas. Yogyakarta. Andi

Wulandari, Rachman \& Nisman(2016). Seksualitas Pada Wanita Setelah Total Abdominal Histerektomi. Journal of Nursing Care and Biomolecular-(2016).Vol 1.38. 